\title{
¿Refugios de la fe o sextantes en tiempos seculares? Los nuevos roles de las instituciones religiosas en contextos minoritarios
}

\author{
Jordi Moreras \\ Universitat Rovira i Virgili \\ jordi.moreras@urv.cat
}

Resumen: Este texto plantea una reflexión teórica sobre las transformaciones que se operan en las instituciones religiosas en contextos minoritarios. Sus iniciativas de adaptación al medio social les llevan a una progresiva transformación de las funciones que les eran propias en un contexto de origen (en el caso de los colectivos migrantes) o que se derivan de la aceptación de su propia condición minoritaria (respecto a cultos religiosos que convivian junto con tradiciones más numerosas). El resultado es una serie de redefiniciones en relación con lo que se espera de estas instituciones, tanto desde el interior de sus colectivos como por parte de la sociedad en la que se sitúan.

Palabras clave: instituciones religiosas, inmigración, reproducción, estrategias adaptativas

Refugees of faith or sextants in secular times? The new roles of religious institutions in minority contexts

Abstract: This text offers a theoretical reflection on the transformations that take place in religious institutions in minority contexts. Their initiatives to adaptat to the social environment lead them to a progressive transformation of the functions that they had in their places of origin (in the case of migrant groups) or that derive from the acceptance of their own minority status (with respect to other more prevalent religious traditions). The result is a series of redefinitions in relation to what is expected from these institutions, both from within the groups that they represent and from the society in which they are located.

Keywords: religious institutions, immigration, reproduction, adaptive strategies. 


\section{Introducción}

Desde Max Weber, y aún más desde Ernst Troeltsch, la sociología de la religión consideró la importancia de la organización de lo religioso, estableciendo una primera distinción clásica entre secta e iglesia, a la que más tarde Robert Nieburh añadiría denominación y culto, como conceptos especialmente pertinentes en el caso de la sociedad norteamericana. La institucionalización religiosa (o rutinización del carisma, en la terminología weberiana) venía a describir la manera en que lo religioso era organizado, estableciendo las estructuras que debían de consolidar una creencia organizada, ya fueran teológicas (la doctrina, los dogmas, los libros sagrados) o institucionales (las iglesias u organizaciones religiosas, con todo su repertorio de perfiles de especialistas religiosos) (Turcotte y Rémy, 2006). Tanto Weber como Troeltsch entendían que el análisis de la institucionalización religiosa se planteaba desde una perspectiva claramente evolutiva, que daba por sentado que todo grupo sectario pretende convertirse en una organización como una iglesia, y que además la institucionalización parecía ser una condición necesaria para que toda creencia fuera organizada.

Desde la Segunda Guerra Mundial, la sociología religiosa anglosajona se enfrascó en un debate sobre estas distinciones clásicas, para proponer unas tipologías más extensas que pudieran explicar con mayor detalle la organización de lo religioso. El funcionalismo parsoniano favoreció aún más este desarrollo tipológico, al aplicar sobre las diferentes organizaciones religiosas una serie de cometidos y funciones, de los más sencillos a los más complejos. Los primeros tiempos de la revista Social Compass, una de las cabeceras de referencia académica en sociología de la religión, fueron testimonio de este desarrollo teórico que entendía la institucionalización como elemento fundamental para la organización de lo religioso: la religión como mecanismo de fortalecimiento de la integración y cohesión de las sociedades, gracias a la labor de las instituciones religiosas (Houtard, 1960; O’Dea, 1960); y la figura de la parroquia como referente social (Fichter, 1960).

Sin lugar a dudas, la centralidad de la cuestión institucional no solo tendría un amplio recorrido teórico, sino que además serviría para perfilar el desarrollo de una sociología pastoral impulsada desde las iglesias cristianas, como instrumento para poder tomar la temperatura al tono religioso de unas sociedades marcadas por las transformaciones impulsadas desde la modernidad. Esa sociología religiosa tuvo una especial incidencia en Francia y Bélgica, desarrollando una perspectiva eminentemente cuantitativa mediante la que poder evaluar la observancia religiosa de las poblaciones cristianas, y centrando su atención sobre la figura de las instituciones religiosas de base como baluartes en el mantenimiento de la fe, y como punto de partida de la acción pastoral. En España, un ejemplo de este 
enfoque lo encontramos en la obra del sacerdote y sociólogo Rogelio Duocastella, preocupado por la «descristianización» de los emigrantes llegados a Cataluña durante la década de los cincuenta también del pasado siglo, llevó a sugerir el desarrollo de una pastoral católica de acción social sobre estas poblaciones, con el objetivo de retornarlas al camino de la práctica religiosa (con trabajos como su tesis Mataró 1955. Estudio de sociología religiosa sobre una ciudad industrial espanola, de 1961, o Cómo estudiar una parroquia, de 1965¹).

El proceso de individualización generalizado en las sociedades modernas también ha pasado factura a las instituciones religiosas. Las fuentes tradicionales que proporcionaban sustento a las agrupaciones sociales se debilitan, y el interés de antaño por las instituciones religiosas también pierde vigor. La desinstitucionalización parece ser la consecuencia lógica de la individualización religiosa. Según Deirdre Meintel (2014), las instituciones religiosas han tenido que hacer frente a la decidida voluntad para expresar una espiritualidad sin la mediación institucional, y a la dispersión doctrinal que ello supone. Para Peter L. Berger, esta desintegración de las instituciones fuerza a los individuos a tener que buscar alternativas con las que seguir dando sentido a su vida, encontrándose ante el pulso que marcan dos procesos que acompañan la modernidad: el fundamentalismo (que «balcaniza la sociedad, llevando o bien a un conflicto permanente o bien a la coerción totalitaria») y el relativismo («que socava el consenso moral sin el cual no puede subsistir ninguna sociedad») (Berger, 2016: 41). El creciente pluralismo religioso se convierte además en un factor que interroga las pertenencias fijadas, y abre la posibilidad de un eclecticismo religioso que nada tiene que ver con el ecumenismo, y que cuestiona el carácter contingente de las fronteras doctrinales. Si el anterior ecumenismo establecía sus bases sobre la fortaleza de las instituciones religiosas, el contemporáneo eclecticismo que sugiere el pluralismo contribuye a debilitar esa solidez institucional.

Berger reconoce que el pluralismo no solo cambia la naturaleza de las instituciones religiosas, sino también su relación con otras instituciones de la sociedad (ibid.: 94). La aceptación de la diferenciación institucional que impone la modernidad también transforma el papel de las instituciones religiosas en las sociedades actuales, compartimentando y situando las mismas dentro de un progresivo descentramiento y alejamiento de los espacios físicos y simbólicos que constitu-

1 En un trabajo anterior (Moreras, 2015), he analizado cómo el enfoque de esta sociología pastoral, mediante los trabajos de Duocastella, u de otros autores como Pere Negre (El obrero y la ciudad, 1968) y Antoni M. Guell (Capvespre de creences, 1973), consideraba el fenómeno migratorio interior como un factor que estaba provocando un declive de la práctica religiosa en estos barrios periféricos de ciudades catalanas, poblados principalmente por emigrantes procedentes de otras regiones españolas. 
yen nuestra sociedad. La asunción de esta diferenciación sería interpretada por José Casanova (2000) como uno de los indicadores de la secularización religiosa.

Quizá a contracorriente de las lecturas que dan por supuesta esta desinstitucionalización (Moreta, 2006), que suele ser indicada apelando al supuesto abandono de la observancia religiosa y la asistencia a los cultos colectivos, deberíamos detenernos en analizar cómo inciden determinados factores que acompañan la situación de pluralismo religioso que vivimos en la transformación del papel social de las instituciones religiosas. Voy a organizar este texto en tres apartados. En el primero, voy a establecer un breve excurso para armar una aproximación crítica respecto el paradigma culturalista y confesionalista que se está imponiendo a la hora de interpretar la emergencia del pluralismo en nuestras sociedades. A continuación me voy a referir a las transformaciones adaptativas que se operan en estas instituciones, poniendo en evidencia el principio de trasplante y reproducción idéntica e inmutable que se les atribuye. En tercer lugar, revisaré críticamente las funciones que son habitualmente atribuidas a las instituciones religiosas, mostrando el efecto que tiene sobre ellas el hecho de situarse en un contexto minoritario. Las reflexiones finales las dedicaré a apuntar los dilemas que se le plantean a estas instituciones religiosas, entre tomar la decisión de orientar sus acciones hacia el interior de su colectivo (y profundizar en su reproducción) o en interacción activa con respecto al exterior del mismo (aceptando tácitamente una tarea de producción de nuevas identidades y pertenencias).

\section{Sin transición, de lo cultural a lo religioso}

Nos hemos instalado en un paradigma explicativo de las diferentes realidades generadas en torno a los procesos migratorios, que beben de los marcos semánticos construidos en torno a los conceptos de cultura y religión, y sus derivados (como identidad, aculturación o interculturalidad en el primer caso, o secularización, laicidad o pertenencia, en el segundo). La búsqueda de una causalidad cultural y/o religiosa de aquellos fenómenos relacionados con el proceso migratorio sigue siendo un presupuesto fundamental en el tratamiento de la misma, que es dado por sentado, y que en ningún momento es puesto en duda. El éxito de los paradigmas culturalistas de definición de la diversidad ha permitido reificar el componente cultural y, a continuación, el religioso, en la comprensión de estos procesos y problemáticas. Y ello se deba quizá más a la progresiva aceptación de estos argumentos dentro de un marco global de reconocimiento de las singularidades que es incorporado en los debates públicos ${ }^{2}$, que no por haber demostra-

2 Para una crítica más extensa de estos debates, véase el ensayo de Daniel Bernabé La trampa de la diversidad. Cómo el neoliberalismo fragmentó la identidad de la clase trabajadora, Madrid: Akal, 2018. 
do su eficacia explicativa sobre la base de un marco teórico de amplio consenso académico. Identificar en ellas una causa primera que fuera cultural y/o religiosa tiene más de político que de heurístico, porque se da por supuesto que es necesario intervenir para poder corregir las problemáticas que pudieran generarse. $\mathrm{Al}$ determinar que hay que intervenir sobre una problemática que fuera categorizada como «cultural»o «religiosa», era entonces posible desplegar las acciones $\mathrm{e}$ instrumentos que serían propios para cada ámbito.

Identificar la causa de los problemas que tienen que ver con el encaje de la inmigración en nuestra sociedad, con base en razones culturales (en concreto de incomprensión e incomunicación cultural), es consecuencia de la aplicación de una forma de comprender las culturas humanas de una manera ahistórica, determinista y justificativa de todos actos individuales y colectivos. En contexto migratorio, el diferencialismo culturalista nos ha llevado a caer en tres presupuestos erróneos: el del trasplante cultural inmutable, el de la homogeneidad interna de los colectivos inmigrantes, y el de la centralidad del componente cultural en la construcción de las identidades en el seno de estos colectivos. La inmutabilidad homogeneizante de las identidades culturales inmigrantes, tal como como lo expresa el diferencialismo culturalista, se ha convertido en el modo de discurso prevalente en la descripción y percepción de la presencia de colectivos inmigrantes no europeos en las sociedades europeas. La cultura, y su correlato conceptual en el término «comunidad», genera una doble abstracción útil: en primer lugar, para pensar y ubicar en el espacio público a unos y otros colectivos; y en segundo, para establecer una especie de criterio predictivo del comportamiento y la razón de los actos sociales de unos individuos dependiendo de su origen cultural-religioso (Baumann, 2001).

En plena euforia culturalista, y tal como ya he avanzado, se viene a añadir la referencia religiosa a la que se le aplica la misma carga determinista y de inmutabilidad que se aplica al elemento cultural. Partimos de atribuciones genéricas de adscripción a una tradición religiosa determinada, sin contrastar la manera en que se transforma una práctica, una pertenencia, así como el significado de una referencia religiosa, a lo largo de un tránsito migratorio. Incorporamos la diversidad religiosa a la cultural, celebrando su contribución a la pluralidad de nuestra sociedad, al mismo tiempo que esta se incorpora como un nuevo elemento definitorio y categorizante de las realidades migratorias ${ }^{3}$.

\footnotetext{
3 Existe una doble paradoja en nuestra sociedad que nos deja un tanto desconcertados: mientras que el discurso intercultural aboga por el mestizaje cultural, por la mezcla entre culturas, parece que difícilmente podemos convertirnos «a otra cultura» diferente de aquella en la que hemos nacido; por otro lado, la libertad religiosa en una sociedad democrática nos permite que cambiemos de religión, optando por otra espiritualidad diferente de aquella en la que fuimos socializados; no obstante, las diferentes religiones protegen celosamente sus principios
} 
Toda esta previa epistemológica tiene sentido porque quiero formular una crítica de este paradigma culturalista y confesionalista, como forma de poner en evidencia el principio de causalidad que implícitamente se está proponiendo, así como la debilidad de los supuestos explicativos en torno a lo cultural y lo religioso como si se tratase de campos inmutables y desvinculados entre sí. Si se quiere tratar seriamente la religión, quizá deberíamos considerarla como una variable independiente (Kniss y Numrich, 2007: 7), puesto que su función, expresión o práctica no son resultado de una simple reproducción en contexto minoritario.

Esta puntualización es especialmente significativa en relación con las formas de asociacionismo que son desarrolladas por parte de los colectivos migrantes, y que suelen ser clasificadas y conceptualizadas en sus funciones y acciones de acuerdo a esta previa distinción entre lo cultural y lo religioso. El estudio de esta compartimentación ya me ocupó hace unos años con respecto al colectivo marroquí en Cataluña (Moreras, 2007), y la valoración que se hacía de tales expresiones asociativas. Posteriormente, me he dedicado a analizar con más detalle el papel institucional de las mezquitas musulmanas en Europa (Moreras, 2014, 2017), insistiendo en las limitaciones de su reproducción como institución social y los retos que se le planteaban en su interacción con las sociedades europeas. En comparación con otras experiencias asociativas desarrolladas desde otras colectividades religiosas (como las que se presentan en este dosier), es posible plantear una reflexión teórica sobre las transformaciones de estas instituciones religiosas que van asumiendo nuevos roles y funciones, como resultado de una interacción cómoda o abrupta con el contexto social en el que se insertan. Para ello voy a proponer una hipótesis que oriente el desarrollo de este texto: si las instituciones religiosas aspiran a mantener su papel de referencia colectiva en un contexto minoritario, han de ser conscientes de que deben modular sus funciones a las nuevas necesidades que son planteadas por parte del grupo al que quieren orientar, así como asumir nuevos roles que anteriormente no tenían. $Y$ todo este proceso adaptativo debe hacerse manteniendo una tensión esencial entre la voluntad de mantenerse fiel a lo que se considera propio de tal institución, y entre la otra voluntad complementaria de tener que hacer frente a cuestiones que, nominalmente, quizá nunca han sido de su competencia (al menos en su sociedad de origen), pero que deben asumir de acuerdo con las circunstancias. Me gustaría apuntar, además, que este diálogo entre ser genuino y ser adaptativo se ve interferido por parte de una doble proyección de expectativas con respecto a las funciones de estas instituciones. Por una parte, las que se generan en el seno de sus colectivos, que parten de posicionamientos dispares y que consideran que las instituciones

dogmáticos, a través de una ortodoxia que define con claridad las fronteras que las diferencia, anatemizando todo atisbo de sincretismo o mezcla. 
deben cumplir unas funciones concretas o adoptar un perfil determinado. Estos posicionamientos entran en disputa por el control de tales instituciones, de acuerdo con la manera en que se piensa que estas han de actuar en una situación de reconstrucción identitaria. Y por la otra, no hay que olvidar las otras expectativas que son proyectadas por parte de la sociedad en general, y, en especial, por las instituciones públicas, que suelen otorgar una dimensión de representación o interlocución a estas entidades, en cuanto que vienen a establecer un punto de identificación con respecto a un colectivo dado.

\section{Las transformaciones adaptativas}

La clásica contribución de W. I. Thomas y F. Znaniecki sobre el campesino polaco en Estados Unidos (publicada entre 1918-1920 ) ya nos indicaba que no todo quedaba igual tras el tránsito migratorio. En su análisis del proceso de creación de una «nueva sociedad polaco-americana» entre el colectivo de origen polaco emigrado a los Estados Unidos de América a finales del siglo xix y principios del $\mathrm{xx}$, estos autores mostraban cómo el individuo inmigrante lleva consigo sus tradiciones y su cultura, pero no las formas de organización social propias de su país de origen, que serían desarrolladas de nuevo conforme los inmigrantes tiendan a asociarse entre ellos. No obstante, estas no adquirirán «ni su contenido ni su significado original», ante los imperativos que muestra la nueva situación. Esta reconstrucción, según Thomas y Znaniecki, ha de tener en cuenta dos circunstancias: en primer lugar, que este proceso es el resultado de una demanda inmediata e irreflexiva de los valores originales más que de una razonada intencionalidad, por lo que este se convierte en un proceso relativamente lento; y en segundo lugar, que el grupo que forma este colectivo de inmigrantes es mucho menos coherente que el de las comunidades presentes en la sociedad de origen, ya que se compone de personas que llevan mucho más tiempo asentadas en la sociedad receptora que otras (Thomas-Znaniecki, 1974: 1470).

La primera función de esta nueva «sociedad» sería la de desarrollar mecanismos de solidaridad entre los miembros de este colectivo para hacer frente a las contingencias que se derivan de su trayecto migratorio. Pero, además de institucionalizar y formalizar las expresiones de esta solidaridad natural, el marco asociativo que define esta comunidad se convierte en el «órgano social de la comunidad, la fuente de toda iniciativa y el instrumento para llevarlas a cabo» (ibid.: 1522). Una institución, como es la parroquia católica en el caso de la comunidad polaca, se convertiría en el agente que debía promocionar y asegurar el desarrollo

4 Existe una versión abreviada publicada en 2005 por el Centro de Investigaciones Sociológicas. He utilizado la versión de 1974 publicada por Octagon Press en dos volúmenes. 
de esta cohesión social, al mismo tiempo que representa simbólicamente la comunidad originaria, reorganizada y reunida de nuevo. El marco religioso y social que ofrece la parroquia, y sus actividades - a pesar de que estas no muestren un contenido únicamente religioso-, constituye un excelente fundamento para la organización comunitaria, que no solo permite la participación de todos los miembros del colectivo, sin importar su sexo o edad, sino que, además, a diferencia de otros contextos (como el económico o el político), no favorece el desarrollo de luchas internas (ibid:: 1525). De esta manera, la parroquia se convierte en el pilar fundamental sobre el que se desarrolla y materializa la noción de comunidad, hasta entonces inexistente, vagamente formulada y que, a partir de ese momento, aparece como un «ideal común para el conjunto del grupo e inexorablemente perseguido» a partir del marco de la parroquia como organización permanente de la comunidad (ibid.: 1530).

En el marco de este proceso de reconstrucción comunitaria, las aportaciones culturales y espirituales de los colectivos y de sus instituciones, ya sean formales (asociaciones, iglesias, organizaciones) o informales (amistades, núcleos familiares), se plantean en un contexto de progresiva adaptación a los condicionantes del nuevo contexto social en el que se emplazan. En el caso concreto de las referencias religiosas, Ebaugh y Chafetz (2000 y 2002) hablan explícitamente de «cambio adaptativo», ya que, a pesar de que los colectivos inmigrantes intentan trasplantar y reconstruir sus instituciones religiosas, ese proceso solo puede tener una dimensión transformadora. Se revisa con ello una forma de interpretar el proceso de trasplante de prácticas, referencias e instituciones como un proceso que se imaginaba sin cambios ni adaptaciones, y que había sido habitual en la literatura sobre migraciones de los años ochenta en Europa (véase, como ejemplo, el texto de Felice Dassetto y Albert Bastenier L'islam transplanté, 1984, que se considera el libro pionero de los estudios sobre el islam europeo). La evidencia de que prácticas culturales, como también observancias religiosas, adquieren nuevos significados a través de su reproducción en contexto migratorio nos obliga a salir del restrictivo paradigma del trasplante inalterable para encontrar un marco más comprehensivo y explicativo de los procesos de transformación, hibridación y cambio, tanto en lo religioso como en lo cultural. Un ejemplo en este sentido es el estudio de Fortier (2000) sobre las comunidades italianas en Londres, que analiza la evolución de las instituciones religiosas del colectivo a lo largo de su proceso de asentamiento, mostrando las variaciones en el contenido, en la proyección y en la presentación social de estas instituciones religiosas.

Este marco más comprehensivo ha de tener presente que la dimensión de los cambios y las transformaciones que aparecen en el ámbito de las expresiones reli- 
giosas no solo se limita a aquellas que se dan en contexto de inmigración, ya que muchas de ellas se encuentran estrechamente relacionadas con otros procesos de cambio y transformación que se dan en las mismas sociedades de origen. Es por ello que la perspectiva de análisis multisituado es fundamental para llevar a cabo estos análisis contextuales amplios. Hagan y Ebaugh (2003) no solo recuerdan la necesidad de contemplar también los cambios que suceden a las expresiones e instituciones religiosas en origen, sino que plantean una perspectiva según la cual interpretan que el factor religioso interviene no solo en el momento en que los colectivos inmigrantes buscan su espacio en la sociedad receptora, sino también en los diferentes momentos del proceso migratorio, desde la toma de decisión a emigrar, la preparación del viaje, el mismo viaje, la llegada, hasta el rol de las instituciones étnicas o religiosas en favor de su acogida y el desarrollo de los vínculos transnacionales.

La perspectiva de Ebaugh y Chafetz (2002) se inscribe básicamente a nivel institucional, mostrando los tres procesos que, desde su punto de vista (y en el contexto de los Estados Unidos de América), se desarrollan en el seno de las comunidades religiosas reconstruidas en contexto migratorio: el congregacionismo, el retorno a los fundamentos teológicos y la inclusión de colectivos étnica y religiosamente diversos. Según estas autoras, el congregacionismo, como estructura inspirada en la tradición protestante reformada, favorece la constitución de comunidades que se agrupan voluntariamente, se convierte en el modelo organizativo de referencia para los colectivos religiosos minoritarios. De esta manera, estos colectivos religiosos estarían aceptando, como mecanismo funcional para progresar de manera efectiva en su encaje social, una forma de estructurarse como congregaciones religiosas, que posiblemente diferiría de la forma de organización religiosa que sería propia en origen. El congregacionismo, pues, se convertiría en una estructura de oportunidad política (political opportunity structure) (Koopmans y Statham, 2000), a través de las cuales estas comunidades religiosas podrían favorecer su incorporación en el espacio público. La cuestión que se plantea es saber de qué manera encajan las sociedades receptoras (de acuerdo con su consideración social de lo religioso) el desarrollo de procesos de institucionalización religiosa que no coincidan necesariamente con aquellos modelos que se establecen como habituales. Ello podría dificultar su reconocimiento social, invalidando la opción de que estas comunidades pudieran aparecer en el espacio público de una manera activa.

Por otro lado, el retorno a las bases teológicas de la propia tradición religiosa supone a veces una especie de depuración cultural respecto a aquellos elementos que se han ido añadiendo al tronco de la tradición. En el caso concreto del islam 
mundializado, Roy (2003) indicaba que la deculturación es una de las principales características que acompañan el proceso de retorno a los orígenes de la tradición islámica. De hecho, si bien no todas las reformulaciones rigoristas en las diferentes tradiciones religiosas prescinden de componentes culturales particulares (el protestantismo conservador norteamericano siempre se ha inspirado en el componente WASP), algunas de ellas (como las comunidades budistas, ortodoxas e hindús en Norteamérica, citadas por Yang y Ebaugh, 2001) desarrollan procesos de unificación de los criterios que los organizan que tienen una directa relación con esa unificación cultural. Por último, los nuevos roles sociales que juegan estas comunidades religiosas les llevan a romper con la tendencia monoétnica que parecía definirles originalmente, abriéndose a otros colectivos que, sin compartir con ellos esa adscripción cultural, sí que forman parte de la misma comunidad religiosa. No solo esto, sino que los nuevos roles sociales e institucionales que han de cumplir estas comunidades les llevan a compartir proyectos comunes con miembros de otras comunidades religiosas, con los que desarrollar — por ejemplo- iniciativas de diálogo interreligioso.

Lo dicho hasta ahora no excluye el hecho de que las comunidades religiosas también reproduzcan patrones de etnicidad, de una etnicidad que se interpreta como sinónimo del mantenimiento de las referencias propias de origen, pero que se formulan y se proyectan en contextos sociales y culturales bien diferentes. Para Ebaugh y Chafetz (2000: 80-99) esta reproducción se hace a través de la reproducción física de las instituciones religiosas —en especial de su arquitectura externa- tal como era en origen, incorporando prácticas de contenido étnico y con festividades que recuperan el calendario vigente en origen, que dan lugar a ceremonias religiosas formales, o bien mediante prácticas religiosas domésticas y otras prácticas de sociabilidad. La educación de las nuevas generaciones, para que estas sean capaces de mantener vivo el vínculo comunitario, se convierte en el objetivo principal de estos procesos de reproducción. En la perspectiva de los adultos/padres de familia, la socialización étnico-religiosa que han de recibir sus hijos para ser buenos miembros de la comunidad les ha de servir para valorar positivamente ese vínculo, que contiene en sí una referencia y una guía, para mantener la relación con esa sociedad de origen, y al mismo tiempo, para vivir a distancia de una sociedad como la receptora, que a ojos de sus progenitores puede ser conceptualizada de inmoral. No obstante, desde la perspectiva de los mismos jóvenes, estas expectativas son interpretadas de manera bien diferente: la reproducción religiosa no necesariamente supone una reproducción étnica, pues estas nuevas generaciones interpretan que su pertenencia religiosa les ha de servir como activo a la hora de negociar su incorporación en la sociedad en la 
que han nacido y/o formado, y no tanto como forma para poder mantener unos vínculos con una sociedad y una cultura más propias de sus padres que de ellos. La individualización religiosa se expresa en boca de las nuevas generaciones, que desarrollan una aproximación personal a la doctrina, sin tener que cumplir con una pertenencia que, por definición paterna, les obliga a vincularse culturalmente con la religión de sus padres. La creencia se convierte en una opción personal, y ya no en una herencia familiar autoimpuesta, pudiendo esta tomar dos direcciones bien diferenciadas. Por un lado, el desarrollo de una pertinencia más cultural que cultual, en donde se priorice una conciencia de pertenecer a un colectivo con el que se comparte una serie de referencias, y que se materializa en la celebración de determinadas festividades o prácticas colectivas. Y por otro, la formulación de un cumplimiento estricto de la ortodoxia, tanto en lo que hace referencia a la práctica y la ritualidad externa como en la construcción identitaria, distanciándose no solo de las pertenencias sociológicas anteriormente expresadas, sino también de las formas de creencia y práctica tradicionales heredadas del núcleo familiar. La revitalización religiosa que acompaña este segundo perfil nos indica que ya no nos es posible identificar la vitalidad religiosa de los colectivos de origen inmigrante como resultado de un proceso de trasplante (es decir, aceptando que los inmigrantes siguen siendo igual de practicantes que en origen), o bien como respuesta a procesos de exclusión social (el repliegue comunitario como argumento defensivo), sino como combinación de una serie de factores y contextos que no siempre se reproducen por un igual. Su vitalidad religiosa ya no es expresión de su condición inmigrante, sino la de ser miembros activos de la sociedad que, décadas atrás, acogió a sus padres.

Hay que tener presente también el papel que juega el factor transnacional como mecanismo de consolidación de la autoridad en torno a estas instituciones (Ebaugh-Chafetz, 2002). Cuando una institución religiosa se halla vinculada con una estructura transnacional, ya sea fundamentada sobre una dimensión política o doctrinal, puede disfrutar de un predicamento y autoridad diferentes que si se tratara de una institución independiente. La jerarquización de estas estructuras puede servir como mecanismo para consolidar estas instituciones, organizando una red coordinada entre aquellas que estén desplegadas en un territorio concreto, y compartiendo una orientación común. Su autoridad (efectiva y moral) depende más de esta vinculación que de la singularidad de una trayectoria concreta. Es evidente que formar parte de una red permite beneficiarse de un sentido cooperativo, que refuerza y autoriza a cada institución para llevar a cabo sus funciones. Pero esto también conlleva aceptar una orientación dada, e incluso una dependencia que limita el margen de maniobra que estas pudieran tener. 
Tampoco hay que olvidar el papel que juegan los ámbitos políticos en relación con el despliegue de estas instituciones religiosas, a las que se les hace jugar un papel de explícita referencia con respecto a sus colectivos, por no decir de control y regulación de las discrepancias internas. El apoyo organizativo y financiero por parte de determinados países para promover la implantación de instituciones religiosas, con la finalidad de constituir una red de apoyo a sus súbditos expatriados, ha estado siempre presente en la historia de las migraciones ${ }^{5}$. Fortier (2000) ya habla de ello en el caso de los italianos en Londres, como un elemento que cruza de manera sustantiva el tejido asociativo surgido por iniciativa de estos colectivos. El interesante trabajo de Bruce (2019) analiza la penetración institucional de los Gobiernos turco y marroquí en el seno de estas comunidades en diferentes países europeos, destacando que ello constituye un mecanismo fundamental en las tentativas de control político de las mismas mediante la práctica religiosa.

Sea como sea, la reformulación de las identidades religiosas conlleva, consecuentemente, que las instituciones religiosas deban adaptarse a estas nuevas realidades. De la respuesta que estas desarrollen, ya sea convirtiéndose en reductos de la fe (pudiendo adaptar incluso un rol de institución voraz, en el sentido dado por Lewis Coser, 1978, que actuase con un celo controlador y moralizante) o, por el contrario, en sextante desde el que hacer frente a todas estas nuevas circunstancias (tal como sugería Gerd Baumann, 2001, en la que la referencia religiosa sirviera para orientarse en todo momento como un sextante).

Baumann hacía referencia al factor religioso «no como una referencia inmutable, sino como una situación en un contexto» (Baumann, 2001: 93), y acierta con esta metáfora contextual para explicar cómo puede actuar el factor religioso a lo largo del proceso migratorio, de una manera mucho menos determinante y más circunstancial de lo que se acostumbra a pensar. Ahora bien, y sirviéndonos de otra metáfora similar que el propio Baumann había desestimado — la figura de la brújula, por el hecho de que siempre indica la misma posición se esté dónde se esté-, creemos que es posible indicar que no siempre los argumentos, prácticas y discursos religiosos que elaboran los individuos inmigrados se impregnan de ese carácter relativo que se supone del componente contextual al que hace referencia

\footnotetext{
5 La emigración española durante el siglo xx no fue una excepción: tras la reactivación del proceso migratorio hacia Europa durante los años cincuenta, la Iglesia retomó la iniciativa que ya había iniciado en el primer tercio del siglo xx (especialmente en Francia), relanzando las llamadas Misiones Católicas en los principales países de acogida. A mediados de 1962 había ya 23 en Alemania, 13 en Francia, 12 en Suiza, 3 en Bélgica y 1 en Holanda. En 1974 existían un total de 319 capellanes españoles repartidos en estas Misiones (Babiano-Fernández Asperilla, 2009: 125). El Gobierno franquista colaboraba con el asociacionismo católico que proponían las Misiones, manteniendo una complicidad evidente en la recreación nostálgica de una cultura de origen, que entendía que mantener la identidad como español en el contexto de unas sociedades europeas mucho más abiertas y liberales que la española suponía también mantener una integridad como católico resistente a cualquier influencia secularizadora y/o política.
} 
este autor. Ese principio reificador que suele ser criticado en las percepciones que se tienen respecto a lo religioso en inmigración también puede constituir una estrategia a partir de la cual reconstruir referencias religiosas (o étnicas) en estos contextos. La idea de una brújula, cuya aguja magnetizada siempre marca el norte, también puede aparecer como símil de una manera racionalizada y consecuente, de seguir las prescripciones que marcan las ortodoxias religiosas o culturales independientemente del contexto o la situación en que uno se encuentre (es decir, «mantener el recto camino»). En el momento en que se dicta la ortodoxia, los heterodoxos también son emplazados, como aquellos que van en contra de la corriente que es prescrita y que, por lo tanto, les hace «perder de referencia el norte», expresión especialmente adecuada en este caso.

Las metáforas del sextante y la brújula no se excluyen entre sí, sino que en todo caso se complementan, ya que, de acuerdo con lo que propone Baumann, la interpretación reificadora y ortodoxa de una observancia y de una pertenencia religiosa en contexto migratorio supone también una contextualización de tal referencia a esa nueva realidad social en donde se sitúa.

\section{La reformulación de las funciones principales}

Decía Mary Douglas (1996: 75) que las instituciones pueden considerarse agrupaciones sociales legitimadas. Es decir, aquellas funciones que deban cumplir deben estar reconocidas y soportadas sobre el consenso del grupo al que se dirigen. A las instituciones religiosas se les suelen atribuir cinco funciones básicas y se les considera legitimadas para llevarlas a cabo: la atención religiosa (culto), el mantenimiento de la referencia religiosa (doctrina), la constitución de una moral comunitaria (moral), la representación colectiva (interlocución) y la reproducción identitaria (identidad). Al contraste de las circunstancias que son vividas en un marco minoritario, se puede observar cómo son reformuladas estas funciones básicas.

Disponer de un espacio para el culto colectivo parece ser el objetivo y función principal de toda institución religiosa. Podríamos decir que este factor adopta una dimensión estructural, debido al hecho de que en la morfología de las instituciones religiosas que estamos contemplando el espacio destinado al culto ocupa un lugar central. No en vano, toda creencia religiosa está convocada a ser expresada mediante la práctica que, en su dimensión colectiva, es especialmente señalada. Pero hay un elemento que condiciona decisivamente la cuestión de la función de culto colectivo, y que tiene que ver con el rechazo social que despierta que se habiliten estos espacios en determinadas ubicaciones. En el contexto europeo no solo son las comunidades musulmanas las que han concitado el rechazo vecinal 
ante la apertura de sus centros (Moreras, 2009; Astor, 2017), sino también otras comunidades religiosas, lo que denota que el encaje de una pluralidad religiosa que es identificada con la inmigración no está siendo fácil. Sin derivar en norma, este clima de reactividad social ha supuesto que la apertura de los espacios de culto de alguna tradición religiosa minoritaria se lleve a cabo desde la discreción, lo que pone en evidencia la fragilidad que acompaña el ejercicio real de la libertad religiosa. La invisibilidad de los espacios puede también tener un correlato en la presentación pública de determinadas identidades religiosas, que no deja de ser un hecho preocupante ${ }^{6}$. Igualmente, la pauta de transformación que se opera en la ubicación espacial de estos espacios de culto supone un progresivo abandono del principio de proximidad que relacionaba su emplazamiento con el residencial de aquellos que acudirían a estos espacios. El crecimiento de estos colectivos hace que estos espacios sean insuficientes para acoger a todos los fieles y deban desplazarse a otras ubicaciones más alejadas de donde se reside. Este desplazamiento es resultado de una doble combinación de elementos, como sería la búsqueda de emplazamientos más amplios, en donde poder celebrar el culto colectivo, pero también la presión social a desplazar estos lugares de culto, alegando molestias entre el vecindario. La creciente periferización de los espacios de culto de comunidades religiosa minoritarias empieza a tener una dimensión importante. La pérdida de la condición de proximidad y las cuestiones derivadas del rechazo social hacen que la gestión de estos espacios no pueda orientarse únicamente a conseguir las mejores condiciones para el culto, sino también tener que lidiar con todos aquellos inconvenientes derivados del encaje de este centro en un contexto social dado ${ }^{7}$. Es fácil imaginar que el hecho de tener que negociar con esta reactividad más o menos intensa acabe teniendo un efecto sobre la manera en que se proyecta públicamente una pertenencia religiosa, y cómo una institución asume la condición de abanderar una singularidad concreta en la esfera pública.

Desde el punto de vista de la doctrina, las instituciones religiosas parecen incorporar entre sus principales funciones la de ser garantes y continuadores de un legado doctrinal dado. La doctrina se mantiene gracias al trabajo encomendado

\footnotetext{
6 Es una imagen que suelo utilizar en mis formaciones: la de un letrero en castellano y en árabe situado en la puerta de un pequeño oratorio musulmán de una población cercana a Barcelona, en el que se pide a las personas que salgan del mismo que no se aglomeren ni provoquen molestias a vecinos y viandantes. La discreción del oratorio (que no tiene ningún indicador que informe sobre la condición religiosa de este local) parece también proyectarse sobre los fieles que lo frecuentan, que deben apurarse para evitar formar una aglomeración humana que pudiera despertar problemas o suspicacias.

7 Las diferentes situaciones de acomodo y desacomodo sin duda están pasando factura en relación con el encaje de esta pluralidad religiosa. A pesar del esfuerzo de determinadas agencias públicas en favor de proponer recomendaciones de respeto y acomodo de la diversidad religiosa (como la Fundación Pluralismo y Convivencia del Ministerio de Justicia, o la Dirección General de Asuntos Religiosos de la Generalitat de Catalunya), el balance acumula más deberes que haberes. Véase Bilbao, Uriarte y Urrutia (2014).
} 
a los especialistas religiosos, para que desde su liderazgo sea posible mantener su reproducción y su integridad. Es evidente que las instituciones religiosas a las que nos estamos refiriendo no suelen ser productoras sino reproductoras de la doctrina, asumiendo que esta segunda tarea no menos importante, les dota de una parte de la autoridad que les es reconocida desde el punto de vista de su colectivo. Pero la reproducción en sí misma también abre el camino hacia la adaptación de la doctrina a contextos sociales concretos. Es evidente que en este caso podríamos acudir de nuevo a la metáfora de Baumann entre sextante y brújula para referirnos a la contextualización o al textualismo de la doctrina de acuerdo a las interpretaciones que hagan quienes deben ser sus garantes. Pero tanto en un sentido como en otro, el papel de las instituciones religiosas es determinante según entienda cómo hacer frente a las circunstancias que se generan al situarse en un contexto minoritario. Las respuestas, no obstante, pueden ser diferentes, desarrollando posicionamientos que pueden favorecer interpretaciones diferentes de la doctrina ${ }^{8}$. De hecho, es imposible no perder de vista la compleja heterogeneidad interna que es presente en el seno de los colectivos religiosos minoritarios, con enfoques que pueden ser muy distantes entre sí. En este sentido, la clásica noción de campo religioso desarrollada por Pierre Bourdieu nos sirve para comprender el contexto de concurrencia soterrada que sirve para activar una de las dinámicas de cooperación o competencia en el interior de estos colectivos.

Es evidente que la doctrina religiosa proporciona la base necesaria para el desarrollo de una moral comunitaria, capaz de establecer unos parámetros que sirvan para guiar las acciones de los miembros de las comunidades religiosas minoritarias. Esos principios morales pueden coincidir en mayor o menor grado con respecto a otras moralidades que confluyen en la sociedad en general, pero la responsabilidad de estas instituciones tiene que ver mucho más con el mantenimiento y consolidación de estas refundaciones morales en el seno de la comunidad, que no exportar o influir sobre el conjunto de la sociedad. El trabajo es fundamentalmente interno, centrado sobre aquellas cuestiones que de acuerdo a cada doctrina se conviertan en significativas: la disposición ética de los miembros de la comunidad, la atención con respecto a determinados colectivos como mujeres o jóvenes, la relación con aquellos que no son miembros de la comunidad religiosa, las expresiones de solidaridad, etc. Es evidente que la moral establece un criterio de autorregulación interna, y que las instituciones religiosas tienen la misión de reproducirla en el contexto en el que se sitúan. La interiorización de

8 Kniss y Numrich (2007) recurren al concepto «sectarismo», de uso frecuente en la sociología anglosajona, para explicar las relaciones de competencia en el seno de las comunidades religiosas. Esta competencia puede articularse sobre diferentes ejes, que principalmente son referidos desde el punto de vista doctrinal. Lo que está en juego no es un debate teológico sobre la fidelidad a la ortodoxia de las diferentes opciones, sino conseguir que se imponga una determinada orientación doctrinal. Es un tema mucho más político que doctrinal. 
la misma entre los miembros de la comunidad religiosa juega, sin duda, un papel relevante dentro de ese proceso de reconstrucción identitaria. Tanto la doctrina como la moral pueden apelar a la tradición como elemento que legitima la referencia que quiere servir para aglutinar al colectivo. De ahí que las instituciones religiosas muestran una mayor voluntad de recuperar y mantener elementos que los vinculan con lo que es considerado como propio de la tradición, antes que progresar hacia elementos de innovación o transformación de las pautas tradicionales.

Querer ser referencia para el propio colectivo no es sinónimo de ser representantes del mismo. La supuesta interlocución que es proyectada desde la sociedad hacia estas instituciones, para convertirlas en representantes de un colectivo dado, se convierte en un elemento que interfiere en el desarrollo de sus funciones y porque les viene a imponer una responsabilidad respecto al exterior del grupo. Por definición, las instituciones religiosas manejan los asuntos que tienen que ver con su colectivo de referencia. Pero en contexto minoritario, tienen que añadir además las que les llevan a representar al mismo en el contexto de la sociedad en el que se encuentran. $\mathrm{Al}$ añadir a la organización original la interlocución externa, lo que se está planteando es fundamentalmente resolver las dudas de representación de unos colectivos, que se piensa que se encuentran agrupados en torno a una institución religiosa. Es evidente que esta función proyectada desde el exterior de las instituciones religiosas supone abrir un terreno de confrontación y disputa que viene a interferir en las dinámicas internas definidas en torno a la disputa por la autoridad en el seno de estos colectivos. También hay que considerar el hecho de que el juego de la interlocución lleva a las instituciones religiosas a tener que participar mucho más activamente en el contexto social en el que se sitúan. El incremento de esta interacción contribuye a incorporar las instituciones y sus colectivos dentro de la escena social, incluso desplazándolos hacia terrenos que se encuentran más allá de lo estrictamente religioso?.

La reproducción de los principios de identidad colectiva parece constituir una función inherente para las instituciones religiosas. Pero tal como he argumentado anteriormente, creo que deberíamos tener presente que, primero, la reproducción

9 Es una cuestión que merecería un análisis más detallado, pero la participación de las instituciones religiosas de colectivos minoritarios en las iniciativas de diálogo interreligioso ha contribuido a incrementar cualitativamente la interacción social de estas entidades con otras que forman parte del contexto social en donde se sitúan. Paul Weller (2009) ofrece una interesante propuesta analítica en este sentido, planteando cómo la participación en tales iniciativas genera un nuevo imaginario público respecto a lo religioso. En estos espacios, suelen ser requeridos no solo desde el punto de vista de su singularidad, sino también con respecto a otras cuestiones, como la promoción de la convivencia o la integración de las poblaciones migrantes. Se alienta su participación en estos ámbitos donde se encuentran, pero al mismo tiempo se les acaba encapsulando dentro de esta dimensión religiosa, y no en otros ámbitos de participación social. Este esquinamiento debería ser analizado con detalle antes de celebrar la reproducción de iniciativas interreligiosas en diferentes contextos sociales. 
no siempre es automática ni se orienta bajo los mismos parámetros que regían en origen. Y, segundo, en consecuencia, el contenido de lo que es transmitido y que debe constituir la urdimbre de la identidad se ve condicionado por el contexto social en donde esta se expresará. Pienso que ambas cuestiones son evidentes, pero seguimos dejándonos llevar por los supuestos infundados que repiten que las identidades son simplemente reproducidas. Las instituciones religiosas acaban asumiendo en contexto minoritario la responsabilidad, compartida con otras instituciones sociales como la familia, para llevar a cabo una acción socializadora, principalmente orientada hacia las nuevas generaciones. Y el contenido de aquello que es transmitido no es solo religioso, sino que también está relacionado con el bagaje cultural de estos colectivos. De esta manera, las instituciones religiosas se convierten en productoras de etnicidad, pues difícilmente se desvinculan los elementos religiosos de los culturales, pues unos encuentran sentido apelando a los otros. En el debate académico aún se sigue discutiendo el papel de la religión en la configuración de diásporas (Cesari, 2013), y de acuerdo con este paradigma la reproducción de las identidades es resultado de una compleja combinación de factores e interacciones. Pero sería importante tener en cuenta que el desarrollo de identidades etnorreligiosas en un marco de relaciones transnacionales no solo sirve para reproducirlas en un contexto diferente al de origen, sino que también sirve para reconfigurar el sentido de las prácticas religiosas colectivas entre lo local y lo global (Eade y Garbin, 2007; Levitt y De la Torre, 2016).

\section{Unas conclusiones sobre cuatro dilemas}

De todo lo dicho hasta ahora, se puede concluir que el papel que han de jugar las instituciones religiosas en contexto minoritario todavía está por escribir. Nos encontramos en un periodo de doble transición con respecto a estas instituciones, para que puedan pasar de ser receptáculo de las referencias de origen a ser facilitadoras de las interacciones con la sociedad en la que se encuentran, y para que su aportación pueda ser leída como una prueba de la pluralización religiosa de la sociedad. En estas transiciones deben ser abordados una serie de interrogantes que quiero plantear de forma sintética en términos de dilemas. No estoy sugiriendo que estos deban formar parte de la agenda futura de estas instituciones (este texto solo tiene una orientación analítica no aplicada), sino que los señalo como parámetros que nos permiten explicar los roles que hoy en día cumplen estas instituciones religiosas, y cito aquellos que ya se apuntan en un horizonte futuro inmediato. Mi intención también es que estos apuntes puedan servir para desarrollar futuras líneas de investigación. 


\section{¿Reproducir o producir?}

Creo que se dan suficientes circunstancias como para poder poner en duda que las instituciones religiosas puedan ser reconstruidas sin alteración alguna en un contexto marcado por la migración y por verse obligado a aceptar una condición minoritaria, como para pensar que su tarea de reproducción social también se llevará a cabo de forma automática. La incierta reproducción cultural de las instituciones religiosas me lleva a pensarla más como una hipótesis y no como un hecho dado por supuesto. Como ya desarrollé en las páginas de esta revista (Moreras, 2017), creo que sería útil hablar de proceso de producción (y no mera reproducción) de estas instituciones, en el sentido de redefinición de sus funciones y de reorientación con respecto a los potenciales receptores de sus acciones, que se encuentran tanto dentro como fuera de su colectivo de referencia.

\section{¿Organización o institucionalización?}

Las instituciones religiosas en contexto minoritario se ven abocadas a desarrollar una doble acción, ya sea hacia dentro del colectivo proponiendo iniciativas de cara a organizarlo internamente, como hacia el exterior del mismo, teniéndose que ocupar de gestionar la interlocución del mismo. Ambas acciones reposan sobre principios de legitimidad diferentes, pero que sirven para poder consolidar el contenido de la autoridad que le es otorgada desde uno y otro ámbito. Los problemas aparecen cuando se intercambian o superponen una sobre otra. Por ejemplo, en el caso concreto que afecta a las comunidades musulmanas, hay que tener presente que los modelos de institucionalización occidental e islámica se fundamentan sobre argumentos referenciales diferentes. La voluntad de parte de las instituciones públicas para forzar a estas otras instituciones dentro de sus propios parámetros, dentro de sus mallas de comprensión de racionalización de la organización colectiva (como decía Douglas, 1996: 141), lleva a formular una serie de expectativas de difícil resolución. Y ello no tanto por incapacidad de sus dirigentes (a pesar de que siguen impregnados de la cultura política de origen en sus formas de gestión de la institución religiosa), sino por el hecho de que reciban el suficiente apoyo para mantener su legitimidad por parte del colectivo. Eso puede explicar el fracaso de algunas iniciativas para agrupar o federar a tales instituciones, al intentar imponer una lógica racionalista en la elección del liderazgo, cuya fuente apela a otros criterios según se entiende desde el seno de estos colectivos. 


\section{¿Refugiarse de o exponerse al entorno social?}

Todo roce desgasta, aunque produce la energía necesaria para que pueda fluir la vida social. El dilema entre mantenerse en un discreto plano, accediendo a servir las necesidades internas del colectivo, o bien exponerse al contexto social no puede leerse únicamente en términos de extensión del capital social de la institución. Tiene que ver fundamentalmente con la capacidad adaptativa que puedan tener estas instituciones, tal como anteriormente he expuesto, y que juzga hasta qué punto pueden ser capaces de asumir los retos que implica el hecho de formar parte de una sociedad plural. Desde el análisis de lo que representan las expresiones cotidianas de lo religioso, Nancy T. Ammerman sugiere que es en la interacción social que estas instituciones pueden hacer progresar su dimensión religiosa amplia:

No son enclaves rodeados de altos muros, donde lo sagrado se mantiene puro y bien defendido. Su capacidad de ser productores poderosos de conciencia de lo sagrado no depende solo de su capacidad de evocar la realidad sagrada en rituales intensos o en explicaciones coherentes del cosmos. Antes bien, su fuerza como productores de cultura sagrada se halla en el grado en que sean capaces de permitir que se mezcle lo sagrado y lo profano (Ammerman, 2016: 197).

Igualmente, hay que tener presente que mantenerse de forma discreta en el espacio público es cada vez más imposible. La manera en que los miembros de las comunidades religiosas minoritarias se hacen presentes en el espacio público ya no se deriva de la emergencia simbólica relacionada con sus lugares de culto colectivo, sino de la manera en que estos interactúan con otras personas, reivindicando en mayor o menor grado su singularidad. La visibilidad de la pluralidad religiosa va evolucionando, y no es tanto por la mayor relevancia de las simbologías edificadas, sino por la manera en que se articulan esas interacciones individuales (Jonker y Amiraux, 2006).

\section{¿Adaptación o concurrencia?}

La adaptación a un contexto nuevo puede ofrecer oportunidades en favor del reconocimiento público de la propia singularidad. Ello supone también incrementar la concurrencia con respecto a otros actores sociales y religiosos que aspiran a este reconocimiento social. Las capacidades de un liderazgo que sea hábil para situar a su colectivo en la escena social son muy valiosas. Pero también la manera en que cada colectivo a través de sus instituciones es capaz de presentarse en sociedad. El trabajo de Joel Robbins sobre las redes globales del pentecostalismo es 
una prueba de esa adaptabilidad que es al mismo tiempo una respuesta a quienes cuestionan su presencia:

El pentecostalismo es propuesta perfecta para los tiempos que corren: predica precisamente el tipo de autosuficiencia y autodisciplina que exige el orden neoliberal; promete una vida mejor por venir para aquellos cuyas vidas actuales están marcadas por la miseria; sana a quienes carecen de acceso a la medicina moderna y, a menudo, también a la curación tradicional; empodera a las mujeres que buscan escapar de los patriarcados tradicionales y les proporciona espacios seguros para la congregación (Robbins, 2010: 58).

Aquello por lo que es criticado proporciona al pentecostalismo su principal fortaleza: «Una vida social densa con rituales proporciona un terreno fértil no para escapar sino para el fortalecimiento institucional» (ibid.: 64).

La síntesis final de estos cuatro dilemas nos lleva a pensar que la cuestión que se proyecta en un futuro inmediato tiene que ver con las aportaciones cívicas de las instituciones religiosas, y su reconocimiento público. De lo que hagan estas más allá de su zona de confort espiritual y referencial dependerá la manera en que progresará el conjunto de instituciones religiosas que se van (re)construyendo en contexto migratorio. Sin duda, un terreno fértil en donde desplegar nuestros futuros esfuerzos analíticos. 


\section{Bibliografía}

Ammerman, Nancy T. (2016). «Altares modernos en la vida cotidiana». En Peter L. Berger. Los numerosos altares de la modernidad (pp. 179.201). Salamanca: Ediciones Sígueme.

Astor, Avi (2017). Rebuilding Islam in Contemporary Spain: The Politics of Mosque Establishment, 1976-2013. Eastbourne: Sussex Academic Press.

Babiano, José y Fernández Asperilla, Ana, (2009). La patria en la maleta. Historia social de la emigración española a Europa. Madrid: Ediciones GPSFundación $1^{\circ}$ de Mayo.

Baumann, Gerd (2001). El enigma multicultural. Barcelona: Paidós.

Berger, Peter L. (2016). Los numerosos altares de la modernidad. Salamanca: Ediciones Sígueme.

Bilbao, Saioa; Uriarte, Luzio y Urrutia, Gorka (2014). «Acomodos' y desacomodos' desde la perspectiva de las minorías». En Dolores MorondoEduardo y J. Ruiz Vieytez (eds.). Diversidad religiosa, integración social y acomodos. Un análisis desde la realidad local en el caso vasco (pp. 83-124). Bruselas: Peter Lang.

Bruce, Benjamin (2019). Governing Islam Abroad: Turkish and Moroccan Muslims in Western Europe. Palgrave-Macmillan, Sciences Po Series in International Relations and Political Economy.

Casanova, José (2000). Religiones públicas en el mundo moderno. Madrid: PPC.

Cesari, Jocelyne (2013). Religion and Diasporas. Challenges of the Emigration Countries. Interact Research Report.

Coser, Lewis (1978). Las instituciones voraces. México: Fondo de Cultura Económica.

Dassetto, Felice y Bastenier, Albert (1984). L'islam transplanté. Bruxelles: EPO, 1984.

Douglas, Mary (1996). Cómo piensan las instituciones. Madrid: Alianza Universidad.

EAde J. Garbin, D. (2007). «Reinterpreting the relationship between centre and periphery: Pilgrimage and sacred spatialisation among Polish and Congolese communities in Britain», Mobilities, 2(3): 413-424.

Ebaugh, H. R. y Chafetz, J. S. (eds.) (2000). Religion and the New Immigrants. Continuities and Adaptations in Immigrant Communities. Walnut Creek: Altamira.

Ebaugh, H. R. y Chafetz, J. S. (eds.) (2002). Religion Across Borders. Transnational Immigrant Networks. Walnut Creek: Altamira. 
Fichter, J. H. (1960). «The Parish and Social Integration». Social Compass, $7(1): 39-47$.

Fortier, Anne-Marie (2000). Migrant Belongings. Memory, Space, Identity. Oxford: Berg.

Hagan, Jacqueline y Ebaugh, Helen Rose (2003). «Calling upon the sacred: Migrant's us of religion in the migration process». International Migration Review, 37(4): 1145-1162.

Houtard, François (1960). «Les variables qui affectent le role intégrateur de la religion», Social Compass, $7(1): 21-38$.

Jonker, Gerdien y Amiraux, Valérie (eds.) (2006). Politics of Visibility. Young Muslims in European Public Spaces. Bielefeld: Transcript.

Kniss, Fred y Numrich, Paul D. (2007). Sacred Assemblies and Civic Engagement. How Religion Matters for America's Newest Immigrants. New Brunswick: Rutgers University Press.

Koopmans, Rudd y Statham, Paul (2000). «Migration and ethnic relations as a field of political contention: an opportunity structure approach"». En Rudd Koopmans y Paul Statham (eds.). Challeging immigration and ethnic relations politics. Oxford: Oxford University Press.

Levitt, Peggy y De la Torre, Renée (2016). «Remapping and rescaling the religious world from below: The Case of Santo Toribio and Santa Ana de Guadalupe in Mexico». Current Sociology, 64(3): 337-355.

Meintel, Deirdre(2014), «Religious collectivities in the era of individualization». Social Compass, 61(2): 195-206.

Moreras, Jordi (2007). Actors i representacions. L'associacionisme d'origen marroqui a Catalunya. Barcelona: Secretaria per a la Immigració.

Moreras, Jordi (2009). Una mesquita al barri. Conflicte, espai públic i inserció urbana dels oratoris musulmans a Catalunya. Barcelona: Fundació Jaume Bofill.

Moreras, Jordi (2014). «Musalas, mezquitas y minaretes: etnografía de las mezquitas en Europa», Awraq, (9): 121-145.

Moreras, Jordi (2015). «Migraciones y religiones. Balance de la producción científica en España (1965-2015)». En F. J. García Castaño, A. Megías y J. Ortega (eds.). Actas del VIII Congreso de Migraciones Internacionales en España. Granada: Instituto de Migraciones, Universidad de Granada.

Moreras, Jordi (2017). «La institución descentrada. Análisis del rol socializador de las mezquitas en Cataluña», Revista Internacional de Organizaciones, (19): 185-205.

Moreta, Ignasi (coord.) (2006). Religions institucionalitzades en una societat laica. Barcelona: Associació Cristianisme al Segle XXI. 
O'DeA, T. F. (1960). «Five dilemmas in the institutionalization of religion». Social Compass, $7(1): 61-67$.

Roвbins, Joel (2010). «Pentecostal Networks and the Spirit of Globalization: On the Social Productivity of Ritual Forms». En Bruce Kapferer, Kari Telle y Annelin Eriksen (eds.). Contemporary Religiosities. Emergent Socialities and the Post-Nation-State (pp. 55-66). New York-Oxford: Berghahn Books.

Roy, Olivier (2003). El islam mundializado. Los musulmanes en la era de la globalización. Barcelona: Bellaterra.

Thomas, William I. y Znaniecki, Florian (2005). El campesino polaco en América. Madrid: Centro de Investigaciones Sociológicas (edición original de 1918-1920).

Turcotte, Paul-André y Rémy, Jean (dirs.) (2006). Médiations et compromis. Institutions religieuses et symboliques sociales. Contributions à une relecture des classiques de la sociologie. Paris: L'Harmattan.

Weller, Paul (2009). «How participation changes things: 'inter-faith', 'multifaith' and a new public imaginary». En Adam Dinham, Robert Furbey y Vivien Lowndes (eds.). Faith in the Public Realm. Controversies, policies and practices (pp. 63-82). Bristol: The Policy Press-University of Bristol.

YAng, Fenggang y EBaugh, Helen Rose (2001). "Transformations in new immigrant religions and their global implications». American Sociological Review, 66(2): 269-288. 